\title{
Measuring ventricular volumes during exercise with vertical long axis cines
}

\author{
Gergely V Szantho ${ }^{1 *}$, Stephen Lyen ${ }^{1}$, Chris B Lawton ${ }^{1}$, Nathan E Manghat', Chiara Bucciarelli-Ducci², \\ Mark Hamilton ${ }^{1}$ \\ From 18th Annual SCMR Scientific Sessions \\ Nice, France. 4-7 February 2015
}

\section{Background}

Imaging cardiac function during exercise remains difficult. Some researchers interrupted the exercise to obtain data, but this is not physiological. Others used real time short axis cine imaging, which presents issues with respiratory motion. La Gerche et al (Circ. Cardiovasc. Imaging 2013) may have solved this by linking the short axis images to the respiratory cycle with additional long axis imaging, but using a not widely available in-house software.

We set out to explore a feasible alternative method of scanning and analysis.

\section{Methods}

A contiguous stack of real time cine steady state free precession (slice thickness $5 \mathrm{~mm}$, no gap, temporal resolution $60 \mathrm{~ms}$, voxel size $\sim 2.8 \times 4.6 \times 5 \mathrm{~mm}$ ) images through the whole heart was performed in the vertical long axis (VLA) plane. VLA is perpendicular to the diaphragm, so the diaphragmatic motion and the breathing cycle can be followed. The VLA plane shows the atrioventricular border, hence reduces error. Resting VLA volumes were compared to standard, gated, short axis volumes.

Eight healthy volunteers underwent continuous aerobic leg exercise with MR-compatible ergometer (Up/ Down, Lode, Groningen, Netherlands) in the MRI scanner (Siemens Avanto 1.5T). Imaging was carried out at rest (10 second/slice to include a full breathing cycle in each cine) and during two stages of exercise, at target heart rates of $150 \%$ and $180 \%$ of resting. The resistance of the ergometer was gradually increased to meet target heart rate, maintaing at least $60 \mathrm{rpm}$. Inspiratory and

${ }^{1}$ Bristol Heart Institute, Bristol, UK

Full list of author information is available at the end of the article expiratory cardiac cycles could manually be selected with following the diaphragm.

\section{Results}

All images were diagnostic regarding endocardium detection, atrioventricular valve position and breathing cycle detection (Image). Standard volumes correlated well with real-time VLA volumes (LVEDV 169.73 $+-39.51 \mathrm{ml}$ vs $210.39+-40.36 \mathrm{ml} \mathrm{r}=0.975 \mathrm{p}<0.0005$, LVESV $68.13+-21.91 \mathrm{ml}$ vs $84.97+-16 \mathrm{ml} \mathrm{r}=0.956 \mathrm{p}<0.001$, LVSV $101.6+-18.91 \mathrm{ml}$ vs $125.42+-26.97 \mathrm{ml} \mathrm{r}=0.931$, $\mathrm{p}<0.005)$. Physiological response was observed:

1) Ejection fraction of both ventricles increased significantly from rest through moderate to higher level of exercise, either measured on inspiration or expiration (from 7 to 13 percentage points, $\mathrm{p}<0.05$ in each cases).

2) Left ventricular stroke volume increased significantly from rest to moderate and from rest to high level of exercise on expiration, $125.42+-26.97 \mathrm{ml}$ vs 135.56 $+-23.35 \mathrm{ml} \quad(\mathrm{p}<0.005)$ and $141.71+-34.78 \quad(\mathrm{p}<0.02)$, respectively.

3) A difference between RV stroke volume on inspiration (RVSVinsp) and RV stroke volume on expiration (RVSVexp) became significant at peak exercise (RVSVinsp 136.24+-43.09ml vs RVSVexp $115.98 \mathrm{ml}$ $+-34.62, \mathrm{p}<0.02$ ).

The latter two findings may show the effect of the respiratory pump on the circulation.

\section{Conclusions}

Our pilot study shows that it is feasible measuring ventricular volumes during exercise, using a widely available sequence and without the need for additional customised software. Further work is being undertaken to confirm these results in a large scale population.
() Biomed Central

C 2015 Szantho et al; licensee BioMed Central Ltd. This is an Open Access article distributed under the terms of the Creative Commons Attribution License (http://creativecommons.org/licenses/by/4.0), which permits unrestricted use, distribution, and reproduction in any medium, provided the original work is properly cited. The Creative Commons Public Domain Dedication waiver (http:// creativecommons.org/publicdomain/zero/1.0/) applies to the data made available in this article, unless otherwise stated. 


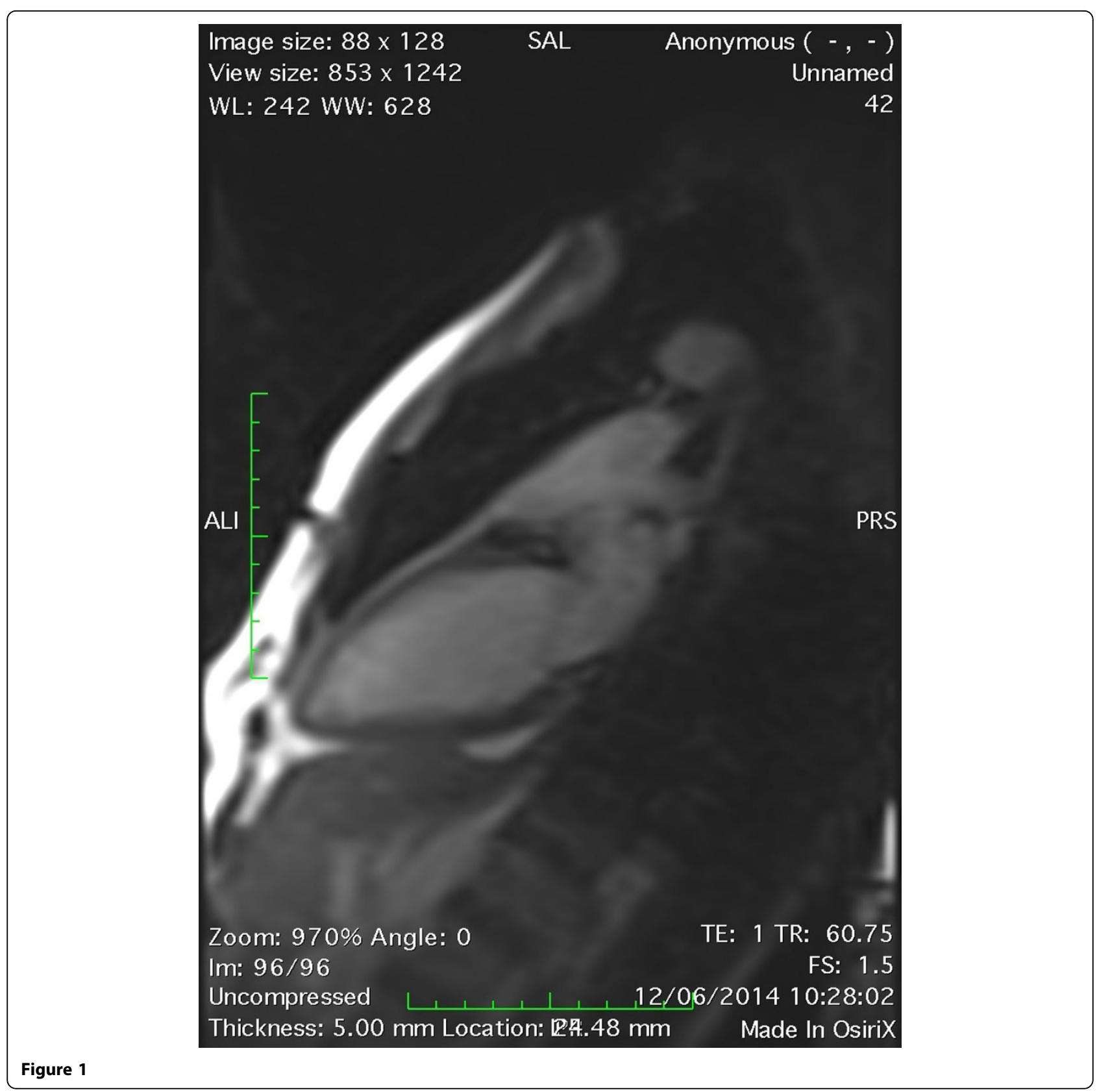

\section{Funding}

Funded by the general research budget of our Institution.

\section{Authors' details}

${ }^{1}$ Bristol Heart Institute, Bristol, UK. ${ }^{2}$ University of Bristol, Bristol, UK.

Published: 3 February 2015

doi:10.1186/1532-429X-17-S1-P386

Cite this article as: Szantho et al:: Measuring ventricular volumes during exercise with vertical long axis cines. Journal of Cardiovascular Magnetic Resonance 2015 17(Suppl 1):P386.

Submit your next manuscript to BioMed Central and take full advantage of:

- Convenient online submission

- Thorough peer review

- No space constraints or color figure charges

- Immediate publication on acceptance

- Inclusion in PubMed, CAS, Scopus and Google Scholar

- Research which is freely available for redistribution 